\title{
Da maternidade (re)negada: mães solteiras e mulheres infanticidas no Ceará oitocentista
}

\author{
Ana Cristina Pereira Limaiti \\ Instituto Federal de Educação, Ciência e Tecnologia do Rio Grande do Norte, Natal, RN, Brasil
}

\begin{abstract}
Resumo
O artigo busca analisar as experiências de mães solteiras e mulheres infanticidas na segunda metade do século XIX, destacando as formas como foram representadas na imprensa cearense do período. As disputas em torno da formulação de padrões hegemônicos de família nos Oitocentos revelaram a multiplicidade de sujeitos e formas de ordenamento familiar, evidenciando histórias de protagonismo feminino na condução de seus lares e na (re)definição de valores e práticas acerca da maternidade. Nesse sentido, tanto as formas de nomear, representar e punir os delitos contra a honra e o crime de infanticídio quanto as maneiras como as mulheres expressaram outros valores e afetos acerca do casamento e dos filhos fazem parte do objeto de estudo aqui apresentado. Para tanto, esta pesquisa utilizou como fontes jornais, documentos oficiais, boletins policiais e textos literários.
\end{abstract}

\section{Palavras-chave}

Mulheres. Maternidade. Família. Infanticídio.

\section{Maternity denied: single mothers and infanticide women in Ceará in the 11th century}

\begin{abstract}
The text analyzes the experiences of single mothers and infanticide women in the second half of the 19th century and the ways in which they were represented in the Ceará press of the period. The disputes over the formulation of hegemonic family patterns in the 19th century showed several subjects and forms of family ordering, evidencing stories of female protagonism in the head of their homes and in the definition of values and practices about motherhood. In this sense, both the ways of naming, representing and punishing crimes against honor and the crime of infanticide, as well as the ways in which women expressed other values and affections about marriage and children are part of this papper. This research used newspapers, official documents, police reports and literature as sources.
\end{abstract}

\section{Keywords}

Women. Maternity. Family. Infanticide. 


\title{
Maternidad negada: madres solteras y mujeres infanticidas en Ceará en el siglo XIX
}

\begin{abstract}
Resumen
El artículo busca analizar las vivencias de las madres solteras y las mujeres infanticidas en la segunda mitad del siglo XIX, destacando las formas en que fueron representadas en la prensa cearense de la época. Las disputas por la formulación de patrones familiares hegemónicos en el siglo XIX mostraron la multiplicidad de sujetos y formas de orden familiar, evidenciando historias de protagonismo femenino en la conducción de sus hogares y en la (re)definición de valores y prácticas sobre la maternidad. En este sentido, tanto las formas de nombrar, representar y sancionar los delitos contra el honor y el delito de infanticidio como las formas en que las mujeres expresaron otros valores y afectos sobre el matrimonio y la niñez forman parte de este estudio. Esta investigación utilizó periódicos, documentos oficiales, informes policiales y textos literarios como fuentes.
\end{abstract}

Palabras clave

Mujer. Maternidad. Familia. Infanticidio.

\section{Introdução}

Eu quero muito as crianças / Alegres, vivas, sadias, / Que vivem como esperanças, / Enchendo o lar de alegrias. // Sempre travessas, inquietas, / Tagarelantes, gentis, / Quais mimosas borboletas / A revoarem sutis. // Eu quero-as muito! E ao vê-las / Quem deixará de querê-las, / Quem deixará de as buscar? // São cheirosas flores / Frutos dos nossos amores / Encantos do nosso lar! (OLYMPIO, 15 jan. 1887).

No soneto acima, publicado no primeiro número da revista $A$ Quinzena, José Olympio descrevia as crianças de forma romantizada, própria da sensibilidade burguesa em fins do século XIX. Nas relações de forças que faziam repercutir modelos ideais de família, forjaram-se definições estanques da condição de criança, vistas como presentes divinos - mimos -, e não como seres sociais, parte de conjunturas culturais e afetivas variadas. Entretanto, a criança, como alvo de cuidado e proteção, é uma invenção moderna, como tem demonstrado a historiografia a partir dos estudos pioneiros de Ariès (1981). A concepção de infância não é atemporal e sua historicidade está ligada às transformações econômicas estruturais, bem como às mudanças comportamentais no âmbito familiar.

Inserida no conjunto de aspirações burguesas que envolvia a defesa da civilidade, do progresso e da norma e da vigilância no cotidiano das pessoas, a indagação de José Olympio sobre as crianças - "Quem deixará de querê-las?" - parecia 
exprimir um sentimento de ternura e tentava repassar alguma sensação de felicidade ao observar as brincadeiras infantis. Seus versos eram parte de uma visão já compartilhada por muitos - promovida pelo cristianismo e repercutida através de folhetins, romances, canções e até anúncios nos jornais - de que a família era a base da nação; era, por assim dizer, a origem da boa conduta, de valores considerados benéficos para a vida em sociedade - como obediência e respeito. Por isso, o poema de Olympio deveria soar como algo natural, como se para sua pergunta existisse apenas uma resposta. Mas a vontade de ter filhos não era assim tão unânime. Não era independente das condições de classe. O que se percebe é que houve uma longa e múltipla busca por normatizar a maternidade, na qual o casamento foi transformado em parte obrigatória da constituição de um grupo familiar. A circulação dessas ideias e as tentativas de propagar uma espécie de receita para formar uma família (o matrimônio, o nascimento dos filhos, a presença dos avôs e demais parentes) alimentavam preconceitos diversos contra as mulheres que, por algum motivo, não cumpriam o rito. Não se casar antes de conceber ou não querer a criança era notável transgressão.

Foi durante o século XIX que a figura ideal da mãe abnegada e diretamente responsável pela sobrevivência dos bebês ganhou notoriedade no Ocidente, sobretudo atrelada à difusão dos saberes médico-higienistas, às preocupações demográficas e econômicas em torno das ideias liberais de produção e mercado e às insistências filosóficas e educacionais atinentes aos papéis femininos na formulação da "modernidade". A filósofa Badinter (1985) demonstrou como o imaginário coletivo a respeito da maternidade foi sendo construído, ressignificado e difundido a partir do século XVII nas considerações de alguns filósofos e juristas europeus e amplamente trabalhado nos dois séculos seguintes, resultando, ao menos no plano das ideias, na fabricação do "instinto maternal". Ou seja, insistiu-se na repercussão da maternidade e dos cuidados com as crianças como práticas e sentimentos naturalmente atribuídos às mulheres. O panorama geral que ela traçou sobre a elaboração do mito do amor materno contribuiu, especialmente no contexto em que foi produzido, para desnaturalizar o lugar social da mulher e da mãe.

A experiência das mães e os meios pelos quais a maternidade foi construída como valor não podem ser tomados como uníssonos em todas as classes sociais, como observou Badinter (1985). Logo, é preciso insistir que as formulações discursivas e os 
comportamentos esperados, impostos e/ou condenados na construção social da maternidade devem ser investigados a partir de condições históricas particulares, evidenciando processos, múltiplos sujeitos e campos de disputas específicos na fabricação da maternidade e de seus desvios.

Nesse sentido, tomou-se como objeto de estudo a atuação feminina na composição dos quadros familiares, observando as formas como foram tratadas as mães solteiras e as mulheres infanticidas na segunda metade do século XIX. Fragmentos da história de mulheres que desafiavam valores hegemônicos e contrariavam o mito do amor materno foram encontrados nas representações de intelectuais, políticos, médicos e juízes, sobretudo nas páginas dos jornais desse período. As mesmas falas que defendiam modelos ideais de mulher e de mãe, inquiridas a partir da intenção de encontrar as mulheres como sujeitos ativos de sua história, revelaram, indiretamente, o protagonismo feminino na gerência familiar, nas escolhas sobre o futuro dos filhos e nas decisões sobre a maternidade.

Notícias que circularam na imprensa cearense, informações censitárias sobre a composição e chefia dos domicílios, registros policiais, laudos médicos e páginas literárias foram tomados como fontes para analisar a vida de mães solteiras e de infanticidas nos enfrentamentos diante da moral cristã/burguesa, da polícia, da interferência estatal e das violências discursivas sobre honra e amor materno. Este artigo é, portanto, um exercício de análise dos sentidos da maternidade, vista em sua heterogeneidade e como campo de disputa. Os embates em torno do direito/dever das mulheres sobre a maternidade não ficaram concentrados na opressão feminina do século XIX. Os processos de difusão dos modelos ideais e da invenção dos desvios em torno do feminino estão no cotidiano doméstico, na formação escolar, nas representações midiáticas e atravessam todos os âmbitos da vida social. A relevância desse tema está na percepção das continuidades históricas que perpassam pelas experiências maternas na atualidade, bem como na necessidade de reafirmar que as mudanças nas relações de gênero não são casuais, mas advindas de processos históricos de luta. É preciso, pois, desnaturalizar a maternidade tanto quanto a punição moral - difusa, não por acaso, no imaginário coletivo - do corpo feminino diante da concepção. 


\section{Mães solteiras: circulação de crianças, estigmas e protagonismo familiar}

A pesquisa em jornais da segunda metade do século XIX mostrou ser bastante comum a presença de crianças expostas na cidade de Fortaleza nesse período. Os "expostos" eram as crianças deixadas na porta de alguma família por suas próprias mães. Essa prática vinha de longa data, principalmente em lugares onde não havia sido instalada - como no caso de Fortaleza - nenhuma roda de "enjeitados" ou Casa de Misericórdia com a finalidade de abrigo de recém-nascidos. A doação de bebês perdurou por longo tempo na história da circulação de crianças no Brasil, visto que é muito recente uma interferência sistematizada do Estado sobre a transferência de crianças. Até a década de 1980, a informalidade caracterizava, quase sempre, os processos adotivos, tanto que se tornou comum no meio jurídico a expressão "adoção à brasileira", referindo-se ao registro ou à circulação de crianças sem qualquer mediação legal. Apenas em 2009 foi promulgada a Lei Nacional de Adoção, que tenta disciplinar o processo de transferência de crianças e adolescentes, barrando a adoção direta. A lei também prioriza a permanência da criança dentro da família biológica, salvo quando não há possibilidade comprovada judicialmente. Entretanto, verifica-se que existem permanências na forma de doar e adotar crianças e uma insistência de muitas mães que tentam escolher uma nova família para seus filhos, conforme analisou Ferreira (2015).

Como analisar a historicidade da doação de crianças e suas permanências? Como a produção discursiva sobre a honra feminina, a vulnerabilidade social das mães solteiras e a ausência de assistência infantil nos Oitocentos contribuíram com o fenômeno da circulação de crianças? É preciso situar as noções de abandono e rejeição construídas por grupos hegemônicos (incluindo autoridades governamentais, juristas e religiosos) diante das famílias pobres no Brasil Imperial. A doação de crianças não pode ser entendida simploriamente como irresponsabilidade, desamor ou promiscuidade das mulheres. Fragmentos de histórias familiares e de trajetórias de mulheres pobres solteiras podem elucidar as tensões em torno da exposição de crianças.

Em 1863, logo no raiar do sol, um menino recém-nascido foi encontrado dentro de um uru (cesto de palha) na cerca da casa de um agricultor, nas proximidades de Fortaleza. Esse mesmo homem - José da Costa Lobo - encaminhou a criança a uma senhora - vizinha sua - para que essa pudesse cuidar do menino, dispondo-se a pagar 
as despesas e separando uma cabra para the servir leite. Passaram-se quase dois meses quando José recebeu a visita do pai da criança. Desejava levar o menino consigo. Alegando afeição pelo bebê, aquele que o tinha acolhido se negou a entregá-lo. Contudo, por medo de um processo ou de qualquer envolvimento com a justiça, cedeu às ameaças e o menino foi levado da casa da vizinha que Ihe servia de "ama". Sendo casado e assumindo o filho ilegítimo, a criança não foi aceita em casa do pai biológico e, assim, passou aos cuidados de Eugenia Maria da Conceição, a avó paterna. Mas esse caso noticiado no jornal $O$ Sol não parou por aí. Não satisfeita com a transferência da criança, sua mãe, longe das vistas de Eugenia, entrou na casa, pegou o menininho e o levou novamente à casa de José Lobo, desta vez com uma carta. No papel, a mãe anônima esclareceu que havia escolhido a casa do camponês porque acreditava que "[...] fosse capaz de criar aquele filho do erro, e por isso, o suplicava que o tivesse de novo sob sua guarda". Abriu-se com isso um inquérito judicial. Depois de lá e cá e lá de novo, o pequeno Luiz, que nesse ínterim havia sido batizado pela avó, permaneceu com José Lobo. Porém, ao final da questão, o agricultor teve de pagar os custos do processo e restituir a Eugenia o valor de $150 \$ 000$ réis, quantia atestada por recibo e publicada no jornal O Sol, na edição 319, página 1, de 12 de março de 1863.

O caso do menino Luiz é emblemático para se entender os sentidos do abandono e suas implicações no século XIX. Em estudo sobre as instituições de recolhimento de bebês nos séculos XVIII e XIX, Venâncio (1999) apontou a dinâmica do abandono nas rodas de expostos $^{1}$ no Rio de Janeiro e em Salvador. Depois de contextualizar o aparecimento dessas instituições no Brasil, muito comuns em Portugal desde a Idade Média, o autor discutiu não só o funcionamento desses lugares, mas também as relações sentimentais que perpassavam pela doação das crianças. Pouco se sabia sobre as mães, mas havia indícios que rompiam minimamente esse silêncio. Algumas vezes, como demonstrou Venâncio (1999), bilhetes eram depositados junto às crianças "enjeitadas". A maior parte indicava o batismo do recém-nascido e o dia de seu nascimento, o que, segundo o autor, revela "[...] uma sutil demonstração de afeto maternal" ou a vontade de depois recuperar a criança (VENÂNCIO, 1999, p. 78).

\footnotetext{
1 As rodas de expostos ou rodas de enjeitados eram espaços, geralmente administrados por religiosos, que recebiam recém-nascidos deixados aos cuidados da caridade. O mecanismo da roda - às vezes, apenas um cesto ou portinhola aberta no muro de conventos ou na Santa Casa - permitia o anonimato das pessoas que deixavam os bebês.
}

Educ. Form., Fortaleza, v. 6, n. 2, e4115, maio/ago. 2021

DOI: https://doi.org/10.25053/redufor.v6i2.4115

https://revistas.uece.br/index.php/redufor/index 
Ainda que imperativos morais conduzissem, muitas vezes, a doação de bebês, visto que a ilegitimidade do nascimento condenava essas crianças e a reputação de suas mães, essa não foi a maior motivação do abandono. Segundo Marcílio (2006), a pobreza foi a principal causa da exposição de crianças no Brasil. É evidente que isso não é um fator isolado. Como explicou a autora, condições estruturais associadas à fragilidade econômica das famílias estão na base da doação. Ela discordou da ideia de que uma taxa de natalidade muita elevada entre jovens mães ou mesmo a prostituição estariam entre os primeiros motivos do abandono. Como resultado de suas pesquisas sobre as rodas de enjeitados, verificou que a morte da mãe e/ou do pai, o desamparo de mulheres deixadas por seus maridos, as doenças graves dos recém-nascidos ou ainda 0 nascimento de gêmeos motivavam a entrega de crianças nascidas em famílias mais empobrecidas (MARCÍLIO, 2006).

Dessa forma, é necessário relativizar a ideia de abandono ou rejeição materna ao tratar das crianças expostas. Como notou Fonseca (2012), as "mães abandonantes", na longa história de fabricação da maternidade ideal, tiveram de conviver com julgamentos severos a respeito de sua honra, honestidade e valor. Conforme explicou a autora, "[...] a palavra abandono carrega conotações de uma rejeição emocional, como se a entrega do filho fosse uma escolha consciente das mães em questão" (FONSECA, 2012, p. 17). A mãe de Luiz, portanto, demonstrou notável protagonismo no futuro do seu filho. Sua determinação em escolher uma família para o menino, fruto de um "erro", revelou - além da impossibilidade de criá-lo - preocupação com sua felicidade e com seu lugar no mundo.

O lugar das crianças na composição das famílias pobres urbanas no século XIX é revelador das redes de assistência estruturadas longe do Estado e das formas de garantir a sobrevivência dos pequenos, não necessariamente presos aos pais. Por isso, a circulação das crianças era bem aceita e representava uma prática comum entre os pobres sem que isso se chocasse com a ideia de família que assumiam.

Muitas vezes, durante o século XIX, a autonomia sobre os filhos foi legalmente subtraída das mães solteiras, especialmente quando o Estado interferia no destino das crianças pobres. Muitas famílias foram separadas por interferências da justiça, da polícia e dos abusos de autoridade praticados em prol de interesses políticos ou econômicos. 
Nos embates políticos entre conservadores e liberais, acusações recíprocas eram recorrentes nos jornais diretamente ligados aos partidos. Em uma dessas disputas, o juiz de órfãos de Ipu, ligado ao Partido Liberal, denunciava excessos e intrigas promovidos por seus adversários políticos naquela cidade. Segundo o juiz José Liberato de Carvalho, o Sr. Antônio de Melo Marinho o estava difamando porque havia mandado que devolvesse uma garotinha que havia alugado através de contrato de soldada ${ }^{2}$ sem, contudo, ter cumprido a obrigação de depositar o soldo. A menina era filha de Maria Cândida e havia sido compulsoriamente dada à soldada logo que completou 7 anos de idade. Na ocasião, a mãe, considerada meretriz, não pôde ficar com a filha em razão de sua indigência e de sua suposta incapacidade moral de educá-la. Ao resumir o caso, Carvalho (1884, p. 2) explicou:

\begin{abstract}
Maria Cândida foi meretriz e hoje está casada, queixou-se que sua filha era maltratada em companhia deste bonacho e, que visto já ter casado, tinha garantia de criar sua filha. [...] Foi assim que, entendendo que esse Antônio de Melo que teve a seu serviço a menor sem condição, voltou a sua ira contra mim, que julgo não ter feito ofensa em coisa alguma.
\end{abstract}

Cândida só conseguiu reaver sua filha quatro anos depois de ter sido entregue à soldada, provavelmente porque o juiz de órfãos desejava atingir seus concorrentes políticos. O que chama a atenção nessa notícia é o argumento legal de que a criança poderia ser devolvida à mãe, que passou de "meretriz" a mulher casada. Nesse contexto, vale sublinhar que meretriz não significava estritamente a prática da prostituição. Qualquer mãe solteira era considerada meretriz por ter cometido desonra, e isso foi largamente usado para ampliar os contratos de soldada e usufruir legalmente do trabalho infantil no século XIX (LIMA, 2019).

A insistência do casamento como atestado da honestidade das mulheres acabava por estigmatizar as mães solteiras e os quadros plurais de composição das famílias no século XIX. As mulheres amasiadas, as relações de concubinato e as separadas de seus maridos foram marginalizadas não só pela força dos códigos cristãos, já que as definições de desvios deixavam de ser exclusividade da lgreja e

2 Os contratos de soldada eram mecanismos legais de alugar o trabalho de crianças órfãos ou em condição de indigência que perduraram ao longo do século XIX. O Juizado de Órfãos entregava a criança aos cuidados de um locatário, que deveria conceder abrigo e instrução profissional, ficando obrigado de depositar um soldo em nome da criança.

Educ. Form., Fortaleza, v. 6, n. 2, e4115, maio/ago. 2021

DOI: https://doi.org/10.25053/redufor.v6i2.4115

https://revistas.uece.br/index.php/redufor/index 
passavam a constituir mecanismos legais de criminalização e limitação dos direitos sobre a família na legislação oitocentista (PAPALI, 2009).

A despeito de todas as opressões e condenações que sofriam as mães sem marido, muitas mulheres chefiavam seus fogos, ou seja, eram responsáveis pelo sustento do domicílio, revelando autonomia na formulação de grupos familiares que não correspondiam aos padrões burgueses e cristãos (RODARTE, 2012). Breves informações extraídas do Arrolamento da População de Fortaleza - uma lista nominal dos moradores da cidade elaborada pela Chefatura de Polícia em 1887 - oferecem indícios sobre a labuta das mães solteiras para cuidarem de seus filhos, muitas vezes sem qualquer assistência, além de suas próprias redes de vizinhança.

No Arrolamento de 1887, é possível localizar o endereço de Luiza Ferreira de Sá, Joana Cândida de Oliveira e Rosalina de França. Estas mulheres tinham muito em comum: eram vizinhas; moravam à rua Formosa, uma do lado da outra; eram solteiras e em suas casas não havia nenhum adulto do sexo masculino. Luiza tinha uma filha de 3 anos de idade e morava com Tereza da Conceição (60 anos), sua agregada, e a filha desta. Joana morava com seus dois filhos, uma menina de 13 e um garoto de 6 anos, assim como Rosalina, que também tinha um filho de 15 anos - que trabalhava como pedreiro - e uma menina de 7 anos de idade. As três mulheres eram costureiras (CEARÁ, 1887).

No geral, o espaço de atuação profissional construído por mulheres nesse período estava fortemente ligado aos laços de vizinhança, expressos na indicação de empregos entre parentes e amigas, na oferta de serviços, na circulação de mercadorias e encomendas feitas por vizinhos. No caso das costureiras, é provável que sua clientela fosse conhecida, formada por pessoas que interatuavam cotidianamente. É claro que nem todas as costureiras trabalhavam em sua casa, já que não era inexpressivo o valor das máquinas de costura. A contratação de costureiras começou a crescer nas últimas décadas do século XIX, momento em que também se multiplicaram as revistas de moda e lojas de aviamentos e tecidos. Nesse sentido, as vagas de emprego eram preenchidas por mulheres e meninas que pertenciam à rede de interação das modistas (donas de ateliês que faziam roupas sob medida).

Não é possível afirmar se Luiza, Joana e Rosalina trabalhavam por conta própria ou se eram empregadas em algum ateliê, mas elas demonstram a atuação feminina 
como chefes de família, indicando que muitas mulheres não podiam ser definidas pela imposição da reclusão doméstica e da obediência ao marido. Mesmo com a insistência de uma educação voltada ao recato, o poder público pouco proporcionava a escolaridade e melhores condições de vida para mulheres. Essa realidade, ainda que tenha sofrido sutil mudança nas primeiras décadas da República - quando as possibilidades de emprego formal para o público feminino aumentaram no país -, perdurou nas desigualdades salariais entre homens e mulheres ou na interiorização de atividades praticadas por mulheres, a exemplo do magistério nas séries iniciais, conforme observaram Oliveira e Martiniak (2018).

As mulheres pobres e mães sem marido construíram suas vivências, revelando comportamentos e traços cotidianos bem diferentes daqueles aconselhados pela imprensa do período e reafirmados insistentemente nos espaços de educação feminina, como bem demonstraram Vasconcelos e Paiva (2018).

Diante da imprevisibilidade de ganhos, muitas mulheres pobres nos Oitocentos improvisavam, a cada dia, o sustento de suas famílias, razão pela qual era tão importante consolidar, ampliar e modificar redes de proteção e informação. Quem comprava, quem oferecia, quem podia intermediar, como e onde ganhar mais eram questões que permeavam as conversas das costureiras. Para Dias (1995), a circulação de conhecimentos sobre a cidade, sobre as pessoas ricas e pobres e sobre as autoridades era instrumento essencial de sobrevivência das mulheres, o que envolvia a troca de favores pessoais, apadrinhamentos, concubinatos, além de muito alarido e teimosia. Exatamente por ser um traço fundamental do ganha-pão dessas mulheres, esses saberes e maneiras de agir são tão difíceis de encontrar. Dessa forma, reconstruir traços da atuação das mães solteiras no século XIX impõe um exercício de articulação dos registros não intencionais sobre suas vidas, como as notas em jornais e dados censitários. Nas palavras da autora, "[...] um caleidoscópio de pequenas referências esparsas [...] atesta a sua presença ostensiva, porém de modo fragmentário, pouco deixando entrever sobre seus modos e inserção na sociedade da época" (DIAS, 1995, p. 26). 


\section{Infanticídio: negação ou impossibilidade da maternidade}

No século XIX, o infanticídio e a negação da maternidade foram bastante noticiados na imprensa, período em que, como se viu, a ideia de amor materno ganhou novas representações. Construíam-se associações diretas entre a mulher infanticida e a maldade, apresentada, quase sempre, na perspectiva maniqueísta do cristianismo. Nos periódicos do século XIX, textos sobre "atrocidades" femininas, especialmente quando tratavam de mulheres que tentavam escapar do papel de mãe, foram abundantes e frequentemente usaram uma linguagem enfática e severa.

Em 1865, em espaço destinado à literatura, circulou no jornal $A$ Constituição um texto intitulado "Mulher ou monstro", que abordava os desvios (pecados) das mulheres que esqueciam ou rejeitavam seus papéis formais condicionantes, ou seja, filha, irmã, esposa, mãe e avó. As mulheres que "[...] maldizem tudo e todos, até as castidades mais delicadas, até os próprios filhos", segundo o texto, têm "[...] impresso na fronte o estigma dos culpados". Sobre a maternidade, o periódico reiterava:

\footnotetext{
Em todos os animais da Criação o coração de uma mãe é uma coisa sublime. [...] Mas podemos apontar com o dedo mulheres que se esquecem que o coração de uma mãe deve ser um foco de amor [...]. Essas têm mais maldade no coração do que estrelas tem no céu. De mulheres só têm a forma, por dentro são harpias. Para estas, remorsos, sem vergonha, a quem Satanás marcou a fronte com o estigma do opróbrio, a execração dos homens e a justiça do Criador. ( $A$ Constituição, 16 jul. 1865, p. 3).
}

A mensagem enunciada no texto acima fazia parte de uma rede de discursos que desconsiderava todos os cenários sociais e sentimentais, outorgando, na violência do trato e na estigmatização das mulheres transgressoras, a valorização absoluta da maternidade e a condenação automática das que rejeitavam seus bebês. Santos e Tfouni (2016), analisando a midiatização da prática de infanticídio na atualidade, discutiram os efeitos dessas produções na classificação e repercussão da "mulher-mãe-monstro". Ao problematizar o papel da mídia como veículo de produção de verdade, utilizando conceitos formulados por Foucault, as autoras indicaram que a homogeneidade da definição de mãe faz reproduzir uma lógica de categorização de seu contrário (monstro), o que não pode ser relativizado, já que serve para confirmar o saber-poder que a sustenta como "normal".

Mesmo com novos parâmetros científicos em torno dos aspectos físicos, psíquicos e culturais sobre a gestação e o parto, evidenciam-se continuidades históricas 
ligadas à negação da pluralidade dos comportamentos femininos, numa operação de apagar as mulheres como sujeitos da maternidade. Em razão disso, o infanticídio praticado por mães incomoda por descontruir, em si, os argumentos de sustentação da naturalização do amor materno.

$\mathrm{Na}$ imprensa do século XIX, o infanticídio aparecia nas seções policiais tanto quanto nos artigos de opinião, já que sobre esse crime recaía maior repulsa e afetação moral. A forma como foram noticiados e representados os crimes de infanticídio tinha, além da nítida execração, uma função pedagógica do temor. Ou seja, pretendia repercutir entre as mulheres o medo de se transformar em "monstro" ou criminosa.

É importante insistir aqui na dimensão formativa dos veículos de imprensa, especialmente tratando da consolidação de práticas, comportamentos e opiniões repercutidas e/ou advindas das searas religiosas e judiciárias. A reprodução dessas representações de mulheres e mães "deformadas" exercia grande efeito de discriminação na vida das mulheres pobres e que rompiam padrões. Operavam, com intensidade, inferências na vida de mulheres ricas, que precisavam aderir e repercutir ideais hegemônicos de caracterização do feminino. Conforme apontou Barros (2007), a imprensa e a publicidade têm espaço significativo na definição de modelos sexistas, articulando hierarquias, normatizações e imposições acerca das relações de gênero.

Nas representações de abortos e infanticídios, vale notar um aspecto importante tratado por Pedro (2003) acerca da escrita produzida por homens sobre o corpo feminino. Na posição de domínio do espaço público (imprensa), a fala masculina definia o que era ou o que deveria ser o corpo das mulheres, justificando a existência social feminina na sua função de reprodução de filhos, função essa que, tratada como natural, não poderia fugir à norma e à moral. Assim, o corpo da mulher estava sempre sob suspeição; qualquer alteração poderia indicar sua desgraça.

Em meados da década de 1870, os delitos da jovem Januária foram expostos em um dos jornais de maior circulação de Fortaleza. "Estando grávida e querendo ocultar de seus pais sua desonra", a garota de 17 anos atirou no mato do Alagadiço Novo seu bebê recém-nascido, que, segundo a perícia, morreu asfixiado pelo cordão umbilical. Pelo crime de infanticídio, Januária foi presa (O Cearense, 1874).

Na prática do infanticídio, atrelada à manutenção da honra feminina, estava toda uma trajetória de conflito que envolvia a solidão da mãe, a dissimulação da gravidez, a 
preocupação com o peso da exclusão social e a própria sobrevivência, considerando a expulsão de casa, o desamparo ou a reação violenta da família. Mas esses aspectos foram pouco relativizados nos periódicos e sofreram lentas alterações no campo jurídico.

Em 1861, a condenação das irmãs Ana e Quitéria elucida a nulidade de defesa das mulheres e o pouco espaço de atenuantes no trato do infanticídio. Entre as anotações da Chefatura de Polícia, ficou registrada a prisão de Antônio Luiz Pereira e suas duas filhas, Ana e Quitéria Pereira. Moradores de Pacatuba, os três foram remetidos à Cadeia Pública de Fortaleza. Antônio foi preso por defloramento de suas filhas. Uma delas engravidou - a nota não informou qual delas - e, depois do parto, as moças mataram o bebê e tentaram ocultar o cadáver ( $O$ Cearense, 1861). A violência cometida pelo pai não foi suficiente para livrar as irmãs da pena de reclusão. Isso faz crer que, no entendimento jurídico, a maternidade estava acima de qualquer circunstância. Além disso, a percepção de que as mulheres eram inferiores e de que seu valor era traduzido na conservação da castidade fazia pairar sobre os crimes de estupro certa suspeita com relação ao comportamento feminino, como se fossem culpadas pela violência do outro. Assim, o crime de defloramento praticado pelo pai foi observado pela óptica do domínio masculino. As mulheres e meninas, ainda que em ambiente doméstico, eram vistas como facilitadoras das pulsões sexuais de homens criminosos.

O infanticídio tratado como crime, especialmente com a consolidação da medicina legal, ganhou olhares e sentenças apurados. A austeridade na condenação das mães infanticidas foi lugar de disputas e reverberações nas práticas jurídicas e no saber médico. Conforme analisou Ciochetto (2017), os médicos legistas constituíram um campo importante no âmbito judiciário, enfatizando a dimensão clínica e instaurando, a partir de suas perícias, a ideia de prova na conclusão da "verdade" nas investigações criminais. No Código Penal de 1890, o crime de infanticídio previa prisão por 6 a 24 anos, mas apresentava atenuantes para as mães que, impelidas pelo medo de demonstrar sua desonra, matavam seus bebês. Entretanto, o reconhecimento desses atenuantes foi resultado da grande recorrência da prática infanticida ao longo do século XIX, o que custou para muitas mulheres exposição, dor, escárnio. Diante da reprovação moral quase absoluta do infanticídio, as mulheres exprimiram a impossibilidade de um único padrão sexual e minimante provocaram sutis mudanças na legislação. De tão 
recorrente, o crime precisou ser (re)pensado ou, ao menos, punido de outras maneiras, embora jamais tenha perdido o efeito da estigmatização.

Outro caso de infanticídio reportado nos jornais cearenses chamou a atenção pela repercussão que the foi dada e por seu desfecho. Nos fundos da casa do padre da Sé foi encontrado o corpo de uma menina recém-nascida. A criança foi jogada por sua mãe no riacho Pajeú, cujas águas a levaram até a casa do padre. Maria Adelina da Silva tinha na ocasião a mesma idade que Januária, quando havia sido presa 13 anos antes pelo mesmo ato. Interrogada, Adelina confessou ter tido o bebê no quintal e ter jogado 0 cadáver no riacho. Dois dias antes da prisão da mãe, o laudo da autopsia foi publicado na íntegra no jornal Libertador, contendo minuciosa descrição do corpo. O médico Aphonso de Luna Freire parecia interessado em expor como se constatavam a causa da morte e a comprovação do infanticídio:

[...] os pulmões flutuavam, logo existiam ar em suas vesículas; só podia ser o ar atmosférico introduzido no ato da respiração [...] a ausência de mecônio na parede abdominal constitui prova muito valiosa em favor da fase de vida precedendo a morte real. $O$ começo de cicatrização no cordão umbilical revela uma fase de vida extrauterina [...] A morte foi causada por asfixia por sufocação, mãos ou panos levados ao encontro do nariz e da boca [...] A morte foi ocasionada por meio criminoso. (Libertador, 3 maio 1887, p. 2).

O médico concluiu que a criança teria ainda vivido 36 horas antes de ser sufocada. Entre as observações do Dr. Freire, está o registro de sinais de nutrição. $O$ laudo parecia reconstruir imageticamente as primeiras horas do relacionamento entre a mãe/monstro/infanticida e a menina branca encontrada no riacho. A narrativa de teor científico feita pelo legista parecia desenhar Adelina tampando a boca e o nariz do bebê até provocar sua morte. Dá a ver a possibilidade de Adelina ter amamentado sua filha como forma de reter o choro da criança, evitando ser descoberta. Tal objetividade que comprovava o crime acabava por sugerir que a garota ainda teve tempo de planejar a morte da criança.

A tentativa de se manter no anonimato foi inútil e "Maria Adelina foi recolhida à cadeia, acompanhada de grande multidão de curiosos" (Libertador, 3 maio 1887, p. 2). A notícia do crime se estendeu durante toda a semana no jornal. A garota era agregada da casa de José Antônio Moreira da Rocha - coronel da Guarda Nacional e deputado da Província -, onde havia chegado ainda na tenra infância - "cria mimosa de uma escravizada", conforme anotou o jornal Libertador. Estando muito febril e anêmica, teve 
sua prisão revogada pela $1^{\underline{a}}$ Vara e saiu da cadeia após ter confirmado a paternidade da criança, atribuída a um moço chamado Raimundo, que havia embarcado para o Pará. Ainda segundo o jornal, uma lavadeira a teria auxiliado na hora do parto, desfazendo-se das roupas ensanguentadas posteriormente (Libertador, 6 maio 1887, p. 2). Não se sabe o que aconteceu com Maria Adelina depois disso. No entanto, é possível que a influência do patrão, um importante político local, tenha-lhe garantido a liberdade. Adelina recebeu tratamento diferente do que muitas outras jovens presas que não puderam contar com nenhuma defesa.

Não se descartam os casos de infanticídios ligados à manutenção do emprego e da residência, conforme demonstrou Atayde (2007). Algumas mulheres solteiras já eram mães e ter mais filhos - considerando o sustento de mais um indivíduo e a alteração no ritmo de trabalho da mãe - provocaria uma expulsão da casa onde trabalhavam. Investigando processos-crime, a autora apontou para uma quase nulidade de defesa dessas mulheres. Suas condenações partiam do estatuto de verdade dos peritos e dos juízes, sobrando pouco espaço para suas falas. Contudo, como discutiu a autora, elas próprias sabiam operar valores e condutas assimiladas dos discursos normativos e, quando oportuno, usavam a versão de fragilidade e abandono ao seu favor, tentando firmar seus atenuantes (ATAYDE, 2007).

O medo de serem consideradas desonestas e a falta de apoio diante de uma gravidez antes do casamento marginalizavam as mulheres e suas famílias, o que poderia estar na base dos infanticídios. Mas reduzir a prática do infanticídio ao temor de ser considerada uma meretriz é também sedimentar uma visão estereotipada da mulher, como se esta fosse sempre vítima das circunstâncias morais. Como vimos, mulheres foram (são) sujeitos históricos na formulação dos quadros familiares, criando seus filhos à revelia dos dominantes ou decidindo sobre o momento de ser ou de não ser uma mãe.

\section{Considerações finais}

Muitas mulheres foram descritas como criminosas, monstros ou desalmadas. Outras tantas viveram sem qualquer atenção do Estado, trabalhando sozinhas ou ao lado de seus filhos para continuarem existindo. O que se pode notar é que, na condução de seus fogos, boa parte das mães solteiras pobres protagonizava histórias 
de vida repetidamente silenciadas e/ou depreciadas pelos poderes públicos, pelos intelectuais e pelos agentes religiosos. Muita energia foi gasta na condenação de mulheres que não aceitaram ou não puderam aceitar a norma excludente da castidade e da maternidade condicionada ao casamento. No entanto, ao longo do século XIX, poucas foram as ações de assistência às mulheres pobres, marginalizadas na remodelação dos espaços urbanos e estigmatizadas nos discursos hegemônicos sobre honestidade, educação e trabalho.

O tratamento do infanticídio como desvio e pecado precedeu a produção jurídica do infanticídio como crime, que incorporou, em suas práticas e formas de condenação, a punição de mulheres sem observar suas condições de existência, demorando muito tempo para reconhecer atenuantes. A honra feminina ligada ao papel de esposa e os efeitos discursivos da construção da maternidade ideal geraram condenações quase automáticas das mães solteiras e das mulheres infanticidas - expostas sempre que desvendadas, atreladas ao mal, movidas pelos demônios a quem, por serem mulheres, disseram que eram mais suscetíveis.

Essas falas não pertencem ao passado. Quando existe uma mobilização da imprensa, de representantes do governo e da sociedade em geral para tentar impedir o aborto de uma criança estuprada, como aconteceu em agosto de $2020^{3}$, significa que não discutimos o suficiente acerca da maternidade, do direito ao corpo e do lugar social da mulher na contemporaneidade. Em opiniões diversas sobre esse caso, falou-se de retrocessos, de voltar ao passado onde tais argumentos conservadores justificavam violências latentes. Não se trata de retrocessos; são demonstrações de continuidades históricas, indicando a necessidade de instrumentalizar nossa análise sobre as dominações de gênero.

Pretendeu-se, nestas páginas, contribuir com o debate sobre as violências simbólicas e estruturais construídas em torno da maternidade e da negação de práticas comportamentais diversas diante de uma ideia cristalizada de famílias e mães. Percebeu-se que há conjunturas históricas na definição do amor materno e nos cuidados à infância atribuídos às mulheres, que negaram, enfrentaram e evidenciaram a pluralidade de sentidos e sentimentos sobre seus corpos, sua honra e seus filhos. $\mathrm{Na}$

3 Disponível em: https://cultura.uol.com.br/noticias/12204 em-meio-a-protestos-contra-e-a-favor-meninade-10-anos-estuprada-passa-por-aborto-legal.html. Acesso em: 10 out. 2020.

Educ. Form., Fortaleza, v. 6, n. 2, e4115, maio/ago. 2021

DOI: https://doi.org/10.25053/redufor.v6i2.4115

https://revistas.uece.br/index.php/redufor/index 
composição dos grupos familiares nos Oitocentos, apareceram mães solteiras pobres que tentaram se desvencilhar do controle do Estado sobre seus filhos, mulheres que chefiavam suas casas com muito trabalho, inseridas em redes de solidariedade e insubordinações cotidianas. $\mathrm{Na}$ perseguição dos desvios femininos, mulheres infanticidas se fizeram notar na transgressão da natureza feminina, tal como era definida pelo domínio masculino. Nos fragmentos de trajetórias recolhidos neste estudo, evidenciaram-se lutas e dores femininas na construção de sua própria história.

\section{Referências}

A CONSTITUIÇÃO. Mulher ou monstro. A Constituição, Fortaleza, ed. 156, p. 3, 16 jul. 1865.

ARIÈS, P. História social da criança e da infância. Rio de Janeiro: LTC, 1981.

ATAYDE, M. A. Mulheres infanticidas: o crime de infanticídio na cidade de Fortaleza na primeira metade do século XX. 2007. Dissertação (Mestrado em História) - Programa de Pós-Graduação em História, Universidade Federal do Ceará, Fortaleza, 2007.

BADINTER, E. Um amor conquistado: o mito do amor materno. Rio de Janeiro: Nova Fronteira, 1985.

BARROS, N. C. As mulheres na escrita dos homens: representações de corpo e gênero na imprensa do Recife dos anos vinte. 2007. Dissertação (Mestrado em História) Programa de Pós-Graduação em História, Universidade Federal de Pernambuco, Recife, 2007.

CARVALHO, J. L. Publicações solicitadas. O Cearense, Fortaleza, ed. 40, p. 2, 19 fev. 1884.

CEARÁ. Arrolamento da população de Fortaleza de 1887. Freguesia de Nossa Senhora do Patrocínio - Fortaleza. Livro 355, acervo do Arquivo Público do Ceará.

CIOCHETTO, P. Processos crimes de infanticídio e saberes científicos: a busca pela verdade inscrita nos corpos (Rio Grande do Sul 1891-1919). Aedos, Porto Alegre, v. 9, n. 20, p. 337-361, 2017.

DIAS, M. O. L. S. Quotidiano e poder em São Paulo no século XIX. São Paulo: Brasiliense, 1995. 
FERREIRA, F. Adoção em movimento: grupos de apoio, famílias adotivas e campo (i)legal. 2015. Tese (Doutorado em Antropologia) - Programa de Pós-Graduação em Antropologia, Universidade Estadual de Campinas, Campinas, 2015.

FONSECA, C. Mães "abandonantes": fragmentos de uma história silenciada. Estudos Feministas, Florianópolis, v. 20, n. 1, p. 13-32, 2012.

LIBERTADOR. Infanticídio. Libertador, Fortaleza, ed. 122, p. 2, 3 maio 1887a.

LIBERTADOR. Infanticídio. Libertador, Fortaleza, ed. 125, p. 2, 6 maio 1887b.

LIMA, A. C. Mulheres, crianças e juízes de órfãos: família e trabalho infantil nos oitocentos. Bilros, Fortaleza, v. 7, n. 14, p. 67-84, 2019.

MARCÍLIO, M. L. História social da criança abandonada. 2. ed. São Paulo: Hucitec, 2006.

O CEARENSE. Infanticídio. O Cearense, Fortaleza, ed. 105, p. 3, 24 dez. 1874.

O CEARENSE. Parte oficial. O Cearense, Fortaleza, ed. 1445, p. 1, 31 maio 1861.

OLIVEIRA, L. L.; MARTINIAK, V. L. Liberdade, igualdade e democracia: o ideário republicano e a educação das mulheres no início do século XX no Brasil. Educação \& Formação, Fortaleza, v. 3, n. 9, p. 159-176, 2018.

OLYMPIO, J. As crianças. A Quinzena, Fortaleza, v. 1, n. 1, 15 jan. 1887.

PAPALI, M. A. A legislação de 1890, mães solteiras pobres e o trabalho infantil. Projeto História, São Paulo, n. 39, p. 209-216, 2009.

PEDRO, J. Práticas prohibidas. Práticas costumeiras do aborto e infanticídio no século XX. Florianópolis: Cidade Futura, 2003.

RODARTE, M. M. O trabalho do fogo: domicílios ou famílias do passado (Minas Gerais, 1830). Belo Horizonte: UFMG, 2012.

SANTOS, K. A.; TFOUNI, L. V. A construção da mulher-mãe-monstro: o infanticídio tornado espetáculo na mídia. Revista Nupem, Campo Mourão, v. 8, n. 15, p. 243-261, 2016.

VASCONCELOS, M. C. C.; PAIVA, P. P. Como educar os filhos na casa: a educação doméstica no jornal a Mãi de Familia. Educação \& Formação, Fortaleza, v. 3, n. 2, p. 3756, 2018.

VENÂNCIO, R. Famílias abandonadas: assistência à criança de camadas populares no Rio de Janeiro e em Salvador - séculos XVIII e XIX. Campinas: Papirus, 1999. 
Ana Cristina Pereira Lima, Instituto Federal de Educação, Ciência e Tecnologia do Rio Grande do Norte i- https://orcid.org/0000-0003-2577-9033

Pós-Doutora em História Social pela Universidade Federal do Ceará. É professora do Instituto Federal de Educação, Ciência e Tecnologia do Rio Grande do Norte.

Contribuição de autoria: Desenvolveu a pesquisa e redigiu o texto.

Lattes: http://lattes.cnpq.br/3710078170355375

E-mail: anacris.historiaufc@gmail.com

Editora responsável: Lia Machado Fiuza Fialho

Pareceristas ad hoc: Jane Beltrão e Natália Cavalcanti

\section{Como citar este artigo (ABNT):}

LIMA, Ana Cristina Pereira. Da maternidade (re)negada: mães solteiras e mulheres infanticidas no Ceará oitocentista. Educ. Form., Fortaleza, v. 6, n. 2, e4115, 2021.

Disponível em: https://revistas.uece.br/index.php/redufor/article/view/4115

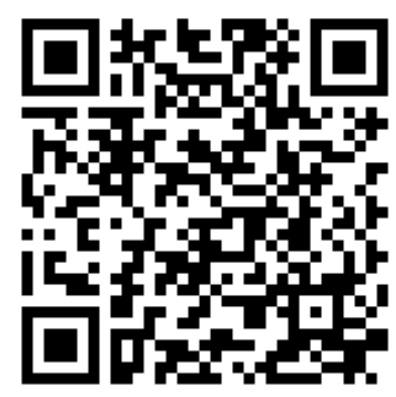

Recebido em 28 de setembro de 2020.

Aceito em 15 de janeiro de 2021.

Publicado em 22 de março de 2021. 